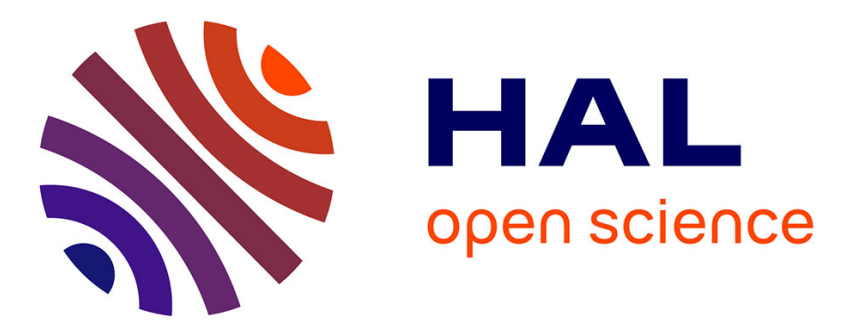

\title{
Cavitation Erosion Resistance Assessment and Comparison of Three Francis Turbine Runner Materials
}

Markku Ylönen, Pentti Saarenrinne, Juha Miettinen, Jean-Pierre Franc, Marc C. Fivel, Tuomo Nyyssönen

\section{- To cite this version:}

Markku Ylönen, Pentti Saarenrinne, Juha Miettinen, Jean-Pierre Franc, Marc C. Fivel, et al.. Cavitation Erosion Resistance Assessment and Comparison of Three Francis Turbine Runner Materials. Materials Performance and Characterization, 2018, 7 (5), 10.1520/MPC20180015 . hal-01929313

\section{HAL Id: hal-01929313 \\ https://hal.science/hal-01929313}

Submitted on 5 May 2020

HAL is a multi-disciplinary open access archive for the deposit and dissemination of scientific research documents, whether they are published or not. The documents may come from teaching and research institutions in France or abroad, or from public or private research centers.
L'archive ouverte pluridisciplinaire HAL, est destinée au dépôt et à la diffusion de documents scientifiques de niveau recherche, publiés ou non, émanant des établissements d'enseignement et de recherche français ou étrangers, des laboratoires publics ou privés.

\section{(c)(1)}

Distributed under a Creative Commons Attribution| 4.0 International License 


\title{
Cavitation Erosion Resistance Assessment and Comparison of Three Francis Turbine Runner Materials
}

\author{
Markku Ylönen, ${ }^{1,2,3,4}$ Pentti Saarenrinne, ${ }^{2}$ Juha Miettinen, ${ }^{2}$ Jean-Pierre Franc, ${ }^{3}$ \\ Marc Fivel, ${ }^{4}$ and Tuomo Nyyssönen ${ }^{2}$
}

Manuscript received January 30, 2018; accepted for publication August 8, 2018; published online October 26, 2018.

1 Université Grenoble Alpes, 1209-1211 Rue de la Piscine, Saint-Martin-d'Heres, Grenoble 38400, France (Corresponding author), e-mail: markku.ylonen@ tut.fi, (iD https://orcid.org/00000002-0092-2537

2 Tampere University of Technology, Korkeakoulunkatu 10, Tampere 33720, Finland

3 Université Grenoble Alpes, CNRS, Grenoble INP, LEGI, 1209-1211 Rue de la Piscine, Grenoble 38400, France

${ }^{4}$ Université Grenoble Alpes, CNRS, Grenoble INP, SIMAP, 101 Rue de la Physique, Saint-Martin-d'Heres, Grenoble 38400, France

\section{ABSTRACT}

Cavitation erosion is the most important erosion mechanism in Francis turbine runner blades. For this reason, knowledge of a material's ability to resist cavitation is important in defining how suitable it is for use in a Francis turbine. In this study, three Francis turbine materials were subjected to cavitation erosion in a high-speed cavitation tunnel. One of the materials was a low-alloy steel, and the other two were stainless steels. The cavitation tunnel produced an annular cavitation field on one face of a cylindrical specimen. The test specimens underwent cavitation erosion until the erosion had reached a maximum penetration depth of about $0.5 \mathrm{~mm}$. The material surface profiles were measured at regular intervals to calculate volume and mass loss. These losses were compared to those of several other materials that had undergone the same tests with the same setup and operational parameters. The materials were compared according to their steadystate erosion rates. The steady-state erosion rate represents a material's ability to resist cavitation erosion once cavitation damage has already started to develop. The low-alloy steel eroded four times faster than the two stainless steels. One of the stainless steels tested here (Stainless steel 1) had the lowest erosion rate, along with another previously tested stainless steel. The other stainless steel (Stainless steel 2) had a slightly greater erosion rate than the first, falling into the same class as other lower-grade stainless steels and a nickel aluminum bronze alloy. The results show that in choosing a turbine blade material, stainless steels outperform 
nonstainless ones. The choice of which type of stainless steel to use is significant in turbines with cavitation problems. The eroded surfaces were analyzed with scanning electron microscopy in order to study the erosion mechanisms, and these studies showed that most of the damage is probably due to low-cycle fatigue.

\section{Keywords}

cavitation, hydro turbine wear, cavitation erosion resistance

\section{Introduction}

The use of renewable energy sources, such as wind or solar power, is increasingly common in electricity production, which means that a large amount of power with modifiable output is required. The current solution is to make more use of hydropower to regulate the power grid, as this can respond to the rapidly changing demands for power. However, when the hydropower turbines have to operate outside their optimum operational values, they experience cavitation and other disturbances. Cavitation erosion is one of the most significant mechanisms for wear in hydro machines. Therefore, information about the turbine material's ability to resist cavitation erosion is vital in avoiding damage or estimating its extent, or both, after it has occurred.

Cavitation occurs in a hydro machine when the local static pressure of a flow falls below a certain limit, typically close to liquid vapor pressure. At this point, the liquid evaporates, forming small vapor bubbles that go with the flow. As the static pressure recovers, these bubbles collapse violently. Cavitation erosion occurs when a cavitation bubble collapses near a boundary, such as a turbine blade. The presence of the boundary causes the cavitation bubble to collapse nonsymmetrically, which leads to the formation of a micro-jet of water that pierces the bubble and a shock wave caused by the collapsing bubble walls [1]. When this micro-jet of water combined with the collapsing bubble ring hits the boundary, the stress on the material exceeds its yield stress, resulting in microscopic damage. This microscopic damage accumulates on the material's surface, eventually leading to fatigue and rupture on a macroscopic scale.

The main parts of a Francis turbine that suffer from cavitation erosion, along with their cavitation types, are: (1) the blade suction-side walls, inlet edge cavitation; (2) the runner blade trailing edges, travelling bubble cavitation; (3) the runner hub walls, interblade cavitating vortices; and (4) the runner blades, leading edge cavitation [2-4]. An example of cavitation damage in Francis turbine runner blades, concentrated on the blade's trailing edges, is presented in Fig. 1. Cavitation may also occur in the draft tube vortex rope of a Francis turbine, but there the cavitation bubbles rarely collapse near any boundary structures.

The development of cavitation erosion in metals has three to four stages: incubation, acceleration, steady-state, and deceleration [5-9]. In the incubation period, an initially virgin material surface experiences plastic deformation, but there is negligible overlap of the cavitation pits. The material's ability to resist the onset of cavitation erosion is closely linked to the length of the incubation period. After the incubation period, the material erosion rate shifts to the acceleration period, when the initial pits start to overlap, and some of the material starts to rupture, i.e., break away. In the steady-state period, the material loss through rupture is in a balanced state. As material is removed, new material becomes exposed to cavitation damage. In the deceleration period, if it is reached, the geometry of the 
FIG. 1

The red circles indicate cavitation damage in a Francis turbine runner blade's trailing edges.

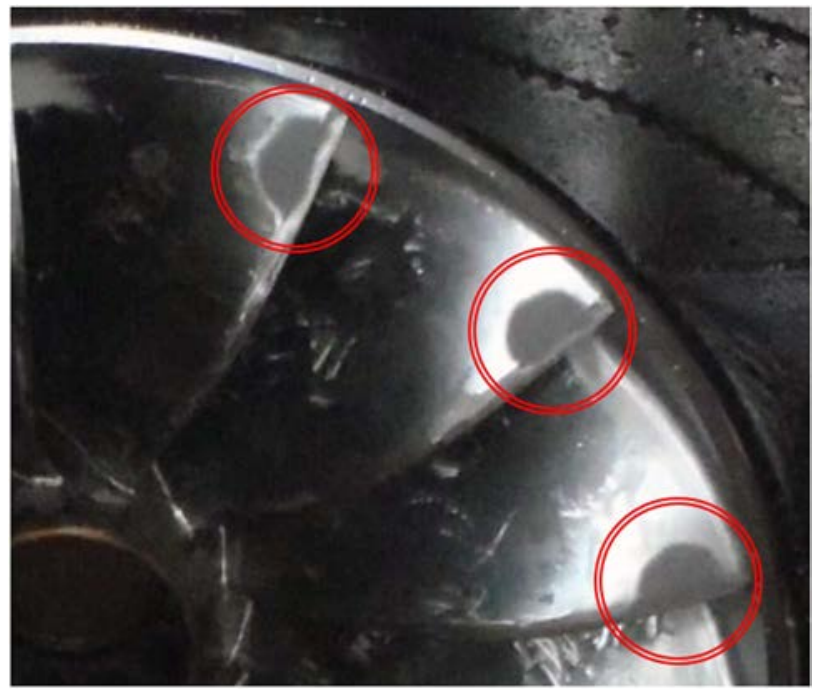

material surface becomes so complex that air and vapor remain in the cavities in the material, thus, potentially damping cavitation impacts and decreasing damage.

There are various methods for assessing a material's resistance to cavitation erosion. The ASTM G32 standardized vibratory cavitation apparatus creates a cavitation cloud in stationary liquid with a vibrating horn (ASTM G32-10, Standard Test Method for Cavitation Erosion Using Vibratory Apparatus [10]). Hattori, Ishikura, and Zhang [11], Hattori and Kitagawa [12], and Hattori and Ishikura [13] used this method to compare the erosion rates of a wide range of different metals. Kendrick, Light, and Caccese [14] used it to compare metals and composites. The ASTM G134-95 cavitation testing apparatus, Standard Test Method for Erosion of Solid Materials by a Cavitating Liquid Jet, provides a high-speed liquid jet that penetrates a static liquid. Cavitation occurs in the turbulent structures in the shear layer between the jet and the static liquid [15]. Soyama and Futakawa [16] compared multiple metals and several other materials using this method. Karimi [17] studied the cavitation erosion resistance of a duplex stainless steel with a vortex cavity generator.

Although many materials have been extensively tested with the G32 static liquid testing method, few have been tested with hydrodynamic methods, as such methods generally require a larger test setup and more complex test setup. The reasons for studying cavitation erosion resistance in a hydrodynamic testing rig, rather than in a static liquid, have been highlighted by Karimi and Avellan in Ref. [18] and by Chahine, Franc, and Karimi in Ref. [15]. In a vibratory cavitation apparatus, such as the G32, the cavitation bubbles are all virtually the same size, and the cavitation damage is distributed evenly and statically over the whole specimen. This means that the cavitation mostly attacks the weaker material phases. In contrast, the hydrodynamic methods produce both different-size bubbles and flow vorticity effects, as well as other interactions with the liquid flow. For these reasons, it is often regarded that a hydrodynamic method, such as was used in this study, provides a better comparison of materials than the static liquid method.

In their fatigue erosion model, Fortes Patella et al. [19] categorized the fatigue mechanism in cavitation erosion as low-cycle fatigue. Low-cycle fatigue occurs when plastic 
deformation occurs with each loading, so that material failure happens after a relatively low number of loading cycles [20]. Balyts'kyi and Chmiel [21] found a correlation between cavitation erosion fracture and the low-cycle fatigue resistance of steel alloys. AboulKasem, Emara, and Ahmed [22] studied the particles removed from the material at different stages of the cavitation erosion process using scanning electron microscopy (SEM). Their study also showed that the erosion mechanism is due to fatigue and that the shape and size of the removed particles changes as the erosion shifts from the incubation period to the mass loss period.

In this study, the materials from three Francis turbines were tested: one low-alloy steel and two different stainless steels (referred to here as Stainless steels 1 and 2). The test setup was the PREVERO high-speed cavitation tunnel (LEGI Laboratory, Grenoble, France) [23]. The tunnel creates an axisymmetric cavitation erosion pattern. The resulting cloud cavitation is very similar to that in a hydrofoil but with a higher intensity. Franc et al. [24] used the cavitation tunnel to study the cavitation erosion of a 7075 aluminum alloy, a C95400 nickel aluminum bronze alloy, a 304L stainless steel, and a A2205 duplex stainless steel, so the materials in this study were compared to those. Deplancke et al. [25] have studied the erosion of ultrahigh molecular weight polyethylene coatings, using the same operating parameters as Franc et al. [24], and they found that such coatings are highly resistant to cavitation. This type of coating could protect against cavitation in hydro machines, if it were economically feasible.

Material microstructure was attempted to be revealed by polishing, etching, and observing with an optical microscope. SEM imaging was used to study the cavitation erosion mechanisms and to pinpoint how the erosion evolves. All three tested materials were observed after they had been subjected to cavitation erosion. The images were taken from different locations and at different magnifications, allowing an overview of the erosion mechanisms at different stages of the erosion to be obtained, as all the stages of erosion coexisted in the eroded specimen, depending on the location of the observed region. The SEM images also allowed the resulting cracks and removed particles to be studied in detail.

\section{Experimental Setup}

The experiments were carried out in a high-speed cavitation tunnel, an image and a schematic of which is shown in Fig. 2. The principle is that 20-mm-thick specimen disks of 100 -mm diameter were placed in the radially diverging test section. The specimen disk thus acts as an opposing wall onto which the inlet nozzle directs the incoming flow. The incoming flow stagnates in the middle of the specimen and then follows the radially diverging channel, which has a smaller cross-sectional area than that of the inlet nozzle. Here, the flow velocity reaches its maximum and the static pressure its minimum. This is where cavitation is initiated (inception). As the channel diverges, the flow velocity decreases, the static pressure increases, and cavitation closure occurs.

The cavitation number in the tunnel is defined in Eq 1:

$$
\sigma=\frac{P_{d}-P_{v}}{P_{u}-P_{d}}
$$

where:

$P_{d}=$ pressure downstream of the test section, $\mathrm{Pa}$,

$P_{u}=$ pressure upstream of the test section, $\mathrm{Pa}$, and

$P_{v}=$ liquid vapor pressure, $\mathrm{Pa}$. 


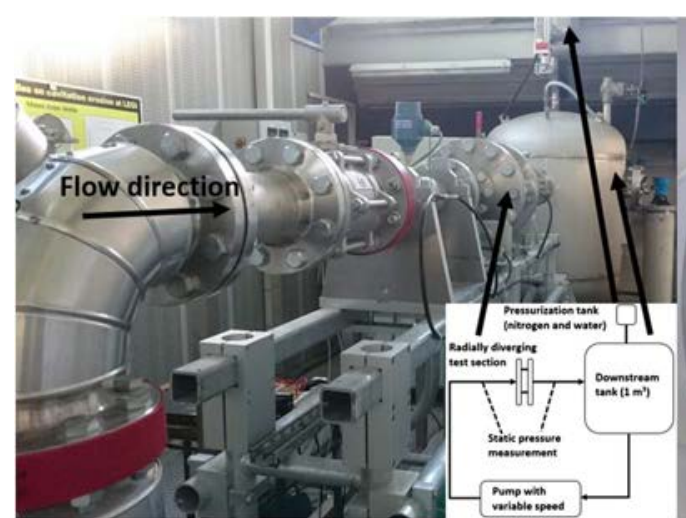

(a)

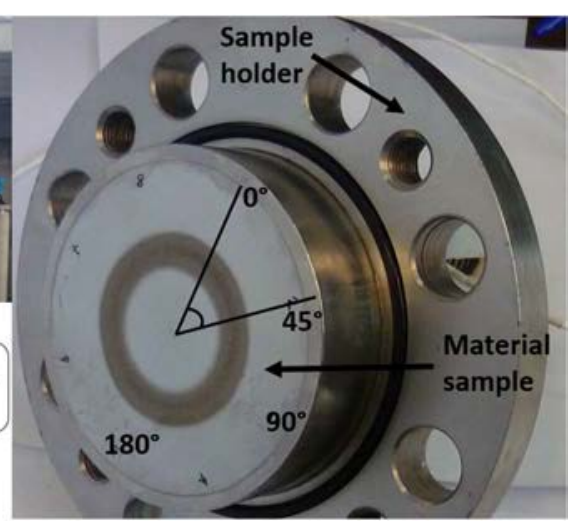

(b)

The cavitation number in this study was 0.87 , corresponding to an upstream pressure of about $4 \mathrm{MPa}$ and a downstream pressure of about $1.86 \mathrm{MPa}$. The downstream section is pressurized by nitrogen gas, and a pump linked to a frequency transformer is used to control both the upstream pressure and the flow velocity in the tunnel. Downstream pressure may be set between ambient pressure and about $3 \mathrm{MPa}$, and the maximum upstream pressure is $4 \mathrm{MPa}$. Similar cavitation tunnels can be studied in more detail in $[6,23,26]$. Fig. 2 presents the overview and schematic of the cavitation tunnel, along with the material specimen and specimen holder.

The test section consists of an inlet nozzle with a $16-\mathrm{mm}$ diameter, followed by a radially diverging channel with a 2.5 - $\mathrm{mm}$ thickness. The cross-sectional area of the channel drops by a factor of 1.6 at the beginning of the radially diverging part. This is where cavitation begins. The cavitation bubbles collapse somewhere between 19-32 mm radial distance from the center of the specimen, with the maximum erosion occurring at a distance of $22 \mathrm{~mm}$ from the center.

The main components of the cavitation tunnel are the downstream tank, the pump, and the test section, as presented in Fig. 2. The downstream tank is pressurized by a separate pressurization tank above the downstream tank. The tunnel is filled with water so that the pressurization tank is almost full; nitrogen gas is added from above through a pressure regulator. The pressure regulator controls the downstream pressure and thus, the overall pressure level of the tunnel. The pump, which is located below the tunnel, increases the upstream pressure. The upstream pressure and the flow speed are controlled by changing the pump rotation speed. Most of the pressure drop occurs in the test section when the tunnel is in a cavitating state.

Three Francis turbine runner blade materials were tested: one low-alloy steel and two stainless steels (named low-alloy steel and Stainless steels 1 and 2). All of the turbines in question were cast, but the exact details of the manufacturing process of the runner blades or the material specimens are the manufacturers' confidential knowledge. The low-alloy steel specimen was cut from an old turbine blade, as well as Stainless steel 1. Stainless steel 2 was a separately cast specimen, cast along with the turbine blades. All cutting was water 
jet cutting, so it was assumed that any changes in the microstructure because of specimen manufacturing were insignificant. Initial polishing and evening of the surface were done by rotating sand paper grinding, with water added on the paper. Any major heating of the specimen was thus avoided.

The specimens were first mirror polished so that the surface was subject to as little initial strain as possible. The surface of the specimen had to be virtually untouched in order to measure the cavitation incubation period as accurately as possible. To achieve a mirrorpolished surface, successive diamond pastes with grain sizes of $3 \mu \mathrm{m}$ and $1 \mu \mathrm{m}$ were used with rotating polishing tissues. The surface was finished off using a colloidal silica suspension with a grain size of $0.03 \mu \mathrm{m}$ and then with yet another type of rotating polishing disk.

As the specimen mass was large compared with the mass of the eroded material (1.2 kg compared with only a few grams), it would be difficult to accurately measure the mass loss because of cavitation erosion by weighing. For this reason, the volume and mass loss were defined through profile measurements. The evolution of the erosion was typically measured at four- to five-hour intervals with a contact profilometer (Form Talysurf 50, Taylor Hobson, Leicester, UK) with a $2-\mu \mathrm{m}$ spherical diamond point providing the contact with the surface. The erosion evolution could be calculated from these surface profiles, which were measured along a radial line running from the center of the specimen center to its outer edge.

Initially, four profiles for each measurement were taken for the low-alloy steel specimen, but this was later found to be inadequate because the erosion evolution had some discrepancies within one individual specimen, so eight profiles were used for the later measurements. Eight profiles had been used for the stainless steel specimens right from the start, as eight corresponded to the eight different azimuthal angles of the specimen (see Fig. 2 for visualization). In order to minimize potential errors, each profile was measured five times along parallel lines, each of them one $\mu \mathrm{m}$ apart, and then these values were averaged out to produce one profile. The specimen underwent erosion until the maximum measured penetration depth in at least one profile reached about $500 \mu \mathrm{m}$. This took about 25 hours for the low-alloy steel and about 65 hours for both the stainless steels.

The surfaces of the fully eroded specimens were analyzed with an SEM (Leo S440, Leica Microsystems, Wetzlar, Germany). In order to form an accurate estimation of all the erosion mechanisms in the material, a great variety of images were taken, from 20 times magnification to up to 5,000 times magnification $(20-5,000 \times)$ from different areas of the specimen, including those areas with little to no erosion, up to the maximum erosion.

A high strain rate is typical in cavitation impacts [27]. The material parameters for the specimens were studied with split Hopkinson pressure bar testing, which is a common testing method for stress-strain relationships with a high strain rate. A strain rate of 2,000 1/s was used for all the steels in this study, i.e., the low-alloy steel and the Stainless steels 1 and 2. As the strain rate is not constant in the plastic region of the specimens, Young's modulus is not measurable with this method, so only the yield stresses were obtained and used to compare the materials.

\section{Calculating Steady-state Volume Loss Rate}

Ten to twenty profiles were obtained for each azimuthal angle for each of the specimen disks, each corresponding to an instant of time in the erosion process. Fig. 3 shows the erosion evolution as a function of time for the low-alloy steel specimen with an azimuthal 
FIG. 3 Cavitation erosion evolution of low-alloy steel. For the sake of clarity, only chosen profiles corresponding to different exposure times are displayed.

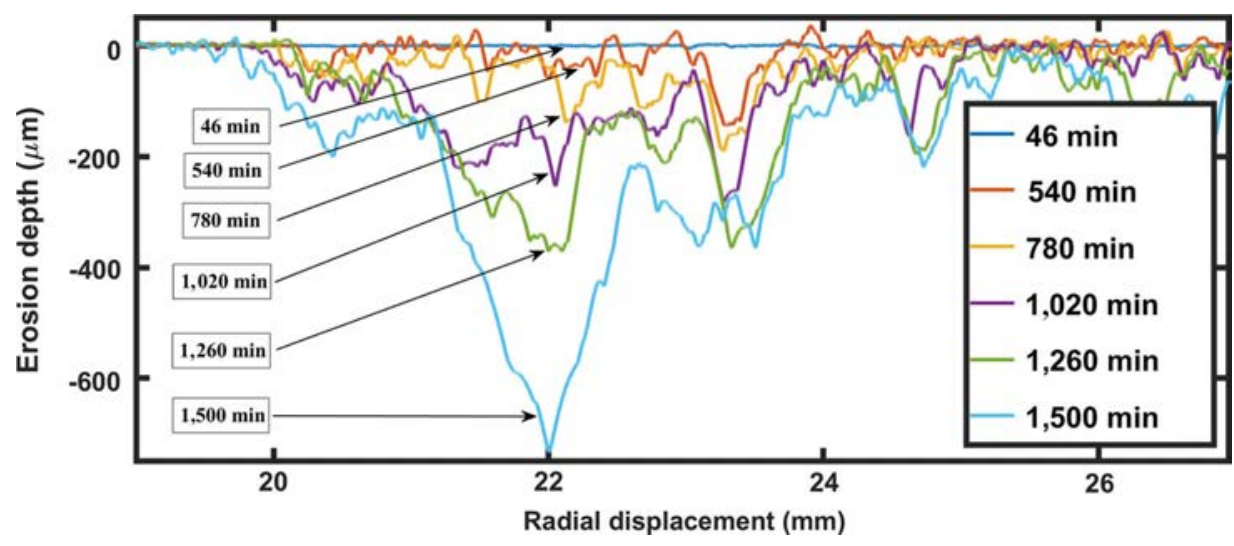

angle of $0^{\circ}$. The maximum penetration depth varies through the different azimuthal angles for the same specimen but is always located in the same radial location, as the erosion pattern is axisymmetric.

The first profile plotted in Fig. 3 shows the transition area between the incubation and acceleration periods that occurs after 46 minutes of exposure to cavitation. The erosion on the specimen is visible to the naked eye, and in the measured profiles, it appears as surface roughness. The blue curve shows the erosion after 25 hours (1,500 minutes), which was the total exposure time of the low-alloy steel and corresponds to a penetration depth of about $750 \mu \mathrm{m}$ in the specimen surface for the azimuthal angle of $0^{\circ}$ (about $450 \mu \mathrm{m}$ for angles $90^{\circ}$ and $270^{\circ}$ ). The initial surfaces, presented in Fig. 4, were virtually flat compared with the advanced erosion stages.

The initial profiles in Fig. 4 are only for one azimuthal angle, but the profiles for the other angles are of a similar order of magnitude. The initial profiles were separated from the subsequent ones, although this procedure has only a marginal effect, as the roughly half-micrometer fluctuations are negligible compared with the up-to-700 micrometer penetration depths. Values above zero in depth were observed for all the materials, especially in the incubation period. This is due to the piling up of the eroding metal because of the cavitation impacts. This is expected in materials with a high ratio between the Young's modulus and the yield stress, such as most metals [7].

As cavitation is assumed to be axisymmetric in the test section, one would assume an axially uniform erosion rate in the disk. To mitigate possible anomalies in the axisymmetricity of the erosion, the stainless steel specimens were turned 90 degrees in the specimen holder after each profile measurement. This procedure was introduced after the experiments with the low-alloy steel, as nonuniformities had been observed in these. Even with this procedure, the erosion depth was not equal in all the specimen azimuthal angles. Fig. $5 \mathrm{a}-\mathrm{c}$ shows photographs of the tested specimen materials after their respective full exposure times.

The volume loss at a given time for a given specimen was calculated from the erosion profiles, as shown in Fig. 4. To calculate the total volume loss over the specimen, the depth value for each point was multiplied by the circumference. This meant that the volume loss 
FIG. 4 Initial surface profiles for the low-alloy steel and Stainless steels 1 and 2.

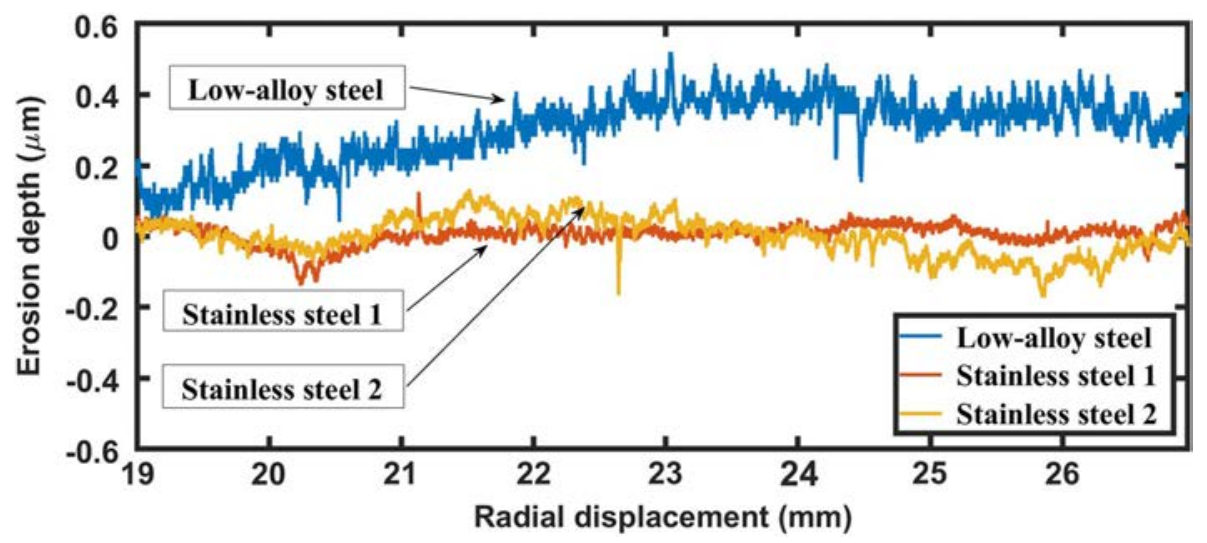

FIG. 5 Material specimens after full exposure time: (a) low-alloy steel, 25 hours, (b) Stainless steel 2, 70 hours, (c) Stainless steel 1, 65 hours. The low-alloy steel is oxidized because of contact with water during the test.

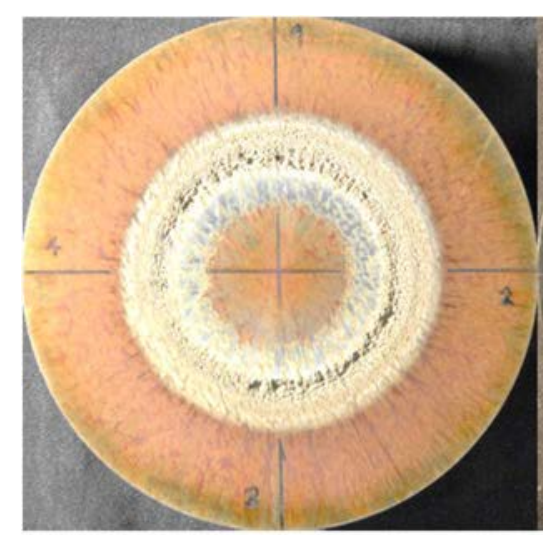

(a)

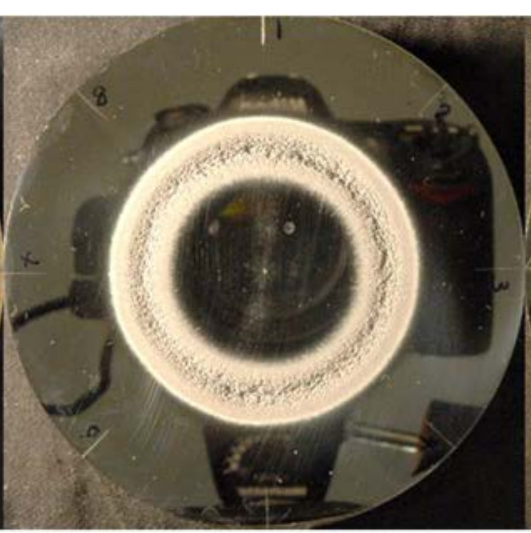

(b)

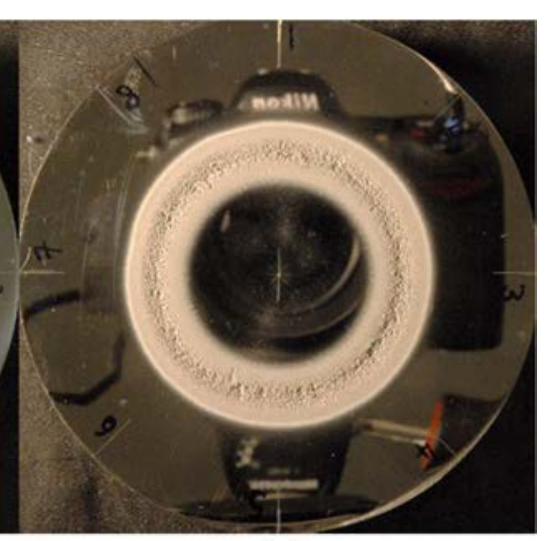

(c)

was calculated for each profile under the assumption that the erosion profile would be the same across the whole specimen. The average volume loss was calculated from the profiles (either 4 or 8 ). Finally, the mass loss was calculated by multiplying the volume loss by the material density.

\section{Results}

\section{MATERIAL PROPERTIES}

An external operator tested the chemical composition of the materials and these are listed in Table 1.

The materials actually contained minor traces of several other elements, but these were irrelevant and have been excluded from Table 1. The materials' mechanical strength was studied with split Hopkinson pressure bar testing, as cavitation impacts tend to have a 
TABLE 1

Material chemical properties. The element contents are expressed as mass percentage.

\begin{tabular}{lcccccccccc}
\hline Material & $\mathrm{Fe}$ & $\mathrm{C}$ & $\mathrm{Cr}$ & $\mathrm{Si}$ & $\mathrm{Mn}$ & $\mathrm{P}$ & $\mathrm{S}$ & $\mathrm{Ni}$ & $\mathrm{Mo}$ & $\mathrm{W}$ \\
\hline Low-alloy steel & 98.69 & 0.205 & 0.0051 & 0.205 & 0.551 & 0.033 & 0.028 & 0.026 & 0.0032 & 0.0077 \\
Stainless steel 1 & 80.00 & 0.046 & 13.80 & 0.238 & 0.726 & 0.026 & 0.014 & 4.385 & 0.201 & 0.219 \\
Stainless steel 2 & 81.67 & 0.02 & 12.6 & 0.45 & 0.58 & 0.025 & 0.005 & 4.2 & 0.45 & - \\
\hline
\end{tabular}

high strain rate. The stress-strain curve of a split Hopkinson pressure bar test is similar to that of conventional compression tests. However, the strain rate changes significantly in the elastic region, and because this impeded the accurate calculation of the Young's modulus, the yield stress was used. The yield stress is a significant parameter for determining whether a cavitation impact has damaged a material [28]. The yield stress may be extracted from the stress-strain curves by fitting a linear equation to both the elastic and the plastic part of the curve and then finding the intersection of these equations. The yield stresses at 2,000 1/s strain rate for all three steels tested in this study are listed in Table 2. For the comparison materials, the values for the yield stresses are taken from the literature on conventional compression testing. The conventional pressure test value is also listed for the low-alloy steel, but there were no listed values for the two stainless steels.

To characterize the material microstructure, the stainless steel specimens were polished, etched, and then studied through optical microscopy. Two examples of the microscope images are presented in Fig. 6a-b. The microstructure study concentrated only on the two stainless steels, as the low-alloy steel was considered an outdated turbine material, and it was only used for erosion rate comparison.

According to the optical microscope analysis, Stainless steel 1 in Fig. 6a is fully martensitic, with small amounts of carbides and other precipitates, as well as larger slag inclusions. The precipitates (possibly carbides) are too small to properly resolve by optical microscopy. The microstructure of Stainless steel 2 in Fig. $6 \mathrm{~b}$ is predominantly martensitic, with a small amount of residual $\delta$-ferrite and carbides and other precipitates, which have a bimodal size distribution. The dark lines in Fig. 6a emerge from the prior austenite microstructure. They were not found in the other specimen, both because of the etching

TABLE 2

Steady-state mass loss and volume loss rates of the studied materials.

\begin{tabular}{|c|c|c|c|c|}
\hline Material & $\begin{array}{l}\text { Steady-state volume } \\
\text { loss rate }\left(\mathrm{mm}^{3} / \mathrm{h}\right)\end{array}$ & $\begin{array}{l}\text { Steady-state mass } \\
\text { loss rate }(\mathrm{mg} / \mathrm{h})\end{array}$ & $\begin{array}{l}\text { Material density } \\
\qquad\left(\mathrm{kg} / \mathrm{m}^{3}\right)\end{array}$ & $\begin{array}{l}\text { Yield stress } \\
\quad(\mathrm{MPa})\end{array}$ \\
\hline Low-alloy steel & 8.95 & 69.79 & $7,800[34]$ & 228,259 at $(2,0001 / s)$ \\
\hline Stainless steel 1 & 1.79 & 13.93 & 7,800 & 452 at $(2,0001 / s)$ \\
\hline Stainless steel 2 & 2.72 & 21.23 & 7,800 & 477 at $(2,0001 / \mathrm{s})$ \\
\hline 7075 Aluminum alloy specimen 1 & 7.88 & 22.12 & $2,810[35]$ & $103-145[35]$ \\
\hline 7075 Aluminum alloy specimen 2 & 8.18 & 22.99 & $2,810[35]$ & $103-145[35]$ \\
\hline A2205 Stainless steel specimen 1 & 2.21 & 17.27 & $7,820[36]$ & $448[36]$ \\
\hline A2205 Stainless steel specimen 2 & 1.31 & 10.25 & $7,820[36]$ & $448[36]$ \\
\hline 304L Stainless steel specimen 1 & 3.29 & 26.29 & $8,000[37]$ & $210[37]$ \\
\hline 304L Stainless steel specimen 2 & 2.83 & 22.64 & $8,000[37]$ & $210[37]$ \\
\hline C95400 Nickel aluminum bronze specimen 1 & 2.86 & 21.34 & $7,450[38]$ & $205[38]$ \\
\hline C95400 Nickel aluminum bronze specimen 2 & 2.30 & 17.17 & $7,450[38]$ & $205[38]$ \\
\hline
\end{tabular}


FIG. 6

Optical microscope images of Stainless steels (a) 1 and (b) 2.

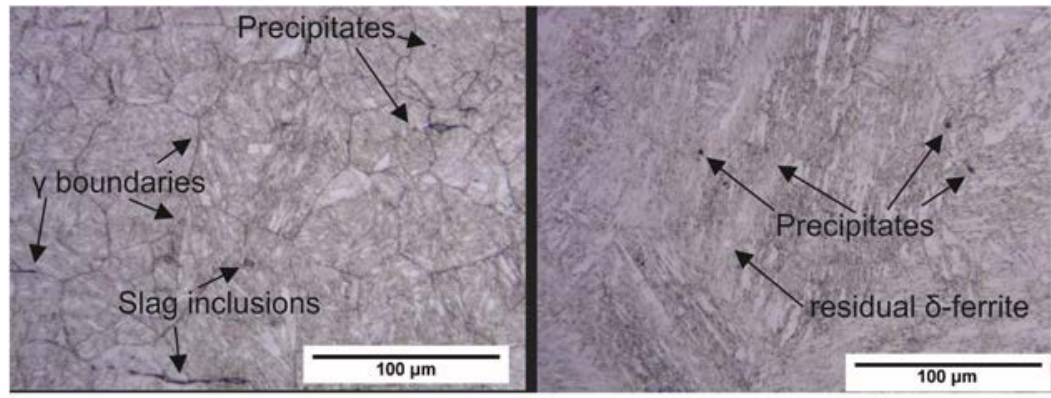

(a)

(b)

treatment not being optimal for the material and the apparently much larger prior austenite grain size.

The notable difference between the microstructures is the considerably finer prior austenite grain size of Stainless steel 1 , measured as $37 \mu \mathrm{m}$, with a standard deviation of $10 \mu \mathrm{m}$, using the mean lineal intercept method as defined by ASTM E112, Standard Test Methods for Determining Average Grain Size [29]. The prior austenite boundaries of the specimen Stainless steel 2 could not be resolved. However, based on the visual observation of block and packet size and the configuration of the lath structure, the prior austenite grain size of Stainless steel 2 is much larger, by approximately an order of magnitude. The prior austenite grain size has been shown to correlate with martensite packet and block size [30], which in turn has a negative correlation with strength. It has been shown that impact resistance and plasticity are particularly sensitive towards prior austenite grain size $[31,32]$, possibly explaining the better resistance of Stainless steel 1 towards cavitation impacts.

\section{STEADY-STATE EROSION RATE}

The volume loss of the eroded materials as a function of time is presented in Fig. 7. The three specimens tested in this study, i.e., the low-alloy steel and Stainless steels 1 and 2 are presented, as are two specimens each of the other materials tested by Franc et al. [24]. Their specimens were smaller than those used for this study, as they were fitted to a specimen holder that holds eight specimens at a time. Their small 16-mm-diameter disks were eroded simultaneously, but for ease of comparison, the erosion of Franc et al.'s small disks was calculated as if they covered the same area as our large disks.

The volume loss curves of the low-alloy steel and both specimens of the 7075 aluminum alloy follow almost the same line, these being the fastest to erode. As some of the specimens had eroded more than the others, defining the steady-state erosion rate from only the final erosion rate is not a fair comparison. The volume loss rate seems to fluctuate even at the relatively steady states of erosion, as presented in Fig. 8. For this reason, the steady-state volume loss rate is rather difficult to define. Therefore, a decision was made to define the volume loss rate as the average of all the volume loss rates between $50 \mathrm{~mm}^{3}$ and $100 \mathrm{~mm}^{3}$.

The incubation time was not used in comparing the materials in this study, because the variance between similar materials was too great, so its effects were removed by linear curve fitting to the linear part of the volume loss curves in Fig. 7 and then defining the $x$-axis intersection of the linear fit. To define the average volume loss rate between $50 \mathrm{~mm}^{3}$ 
FIG. 7 Volume loss of eroded materials.
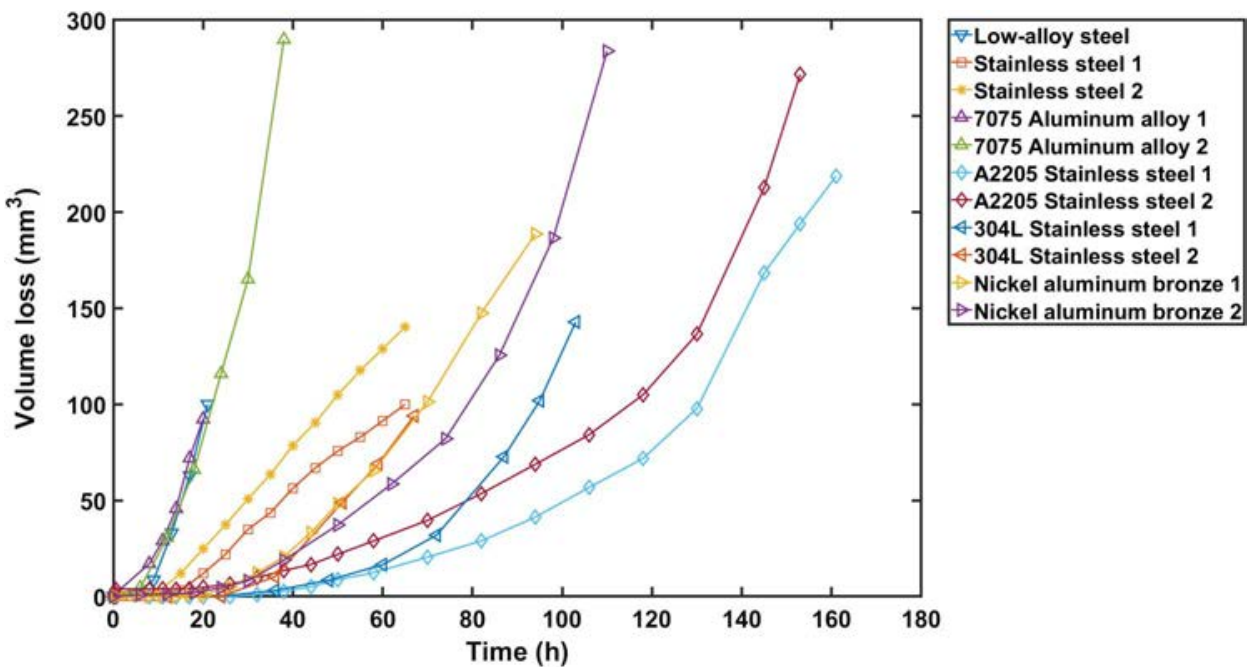

and $100 \mathrm{~mm}^{3}$, a fourth order polynomial function was fitted to the volume loss data. The steady-state volume loss rate was calculated as in Eq 2:

$$
V_{\text {loss rate }}=\frac{100 \mathrm{~mm}^{3}-50 \mathrm{~mm}^{3}}{t_{100}-t_{50}}
$$

where:

$$
\begin{aligned}
& t_{100}=\text { time when erosion volume is } 100 \mathrm{~mm}^{3}, \mathrm{~s} \text {, and } \\
& t_{50}=\text { time when erosion volume is } 50 \mathrm{~mm}^{3}, \mathrm{~s} \text {. }
\end{aligned}
$$

FIG. 8 Volume loss rate as a function of volume loss.
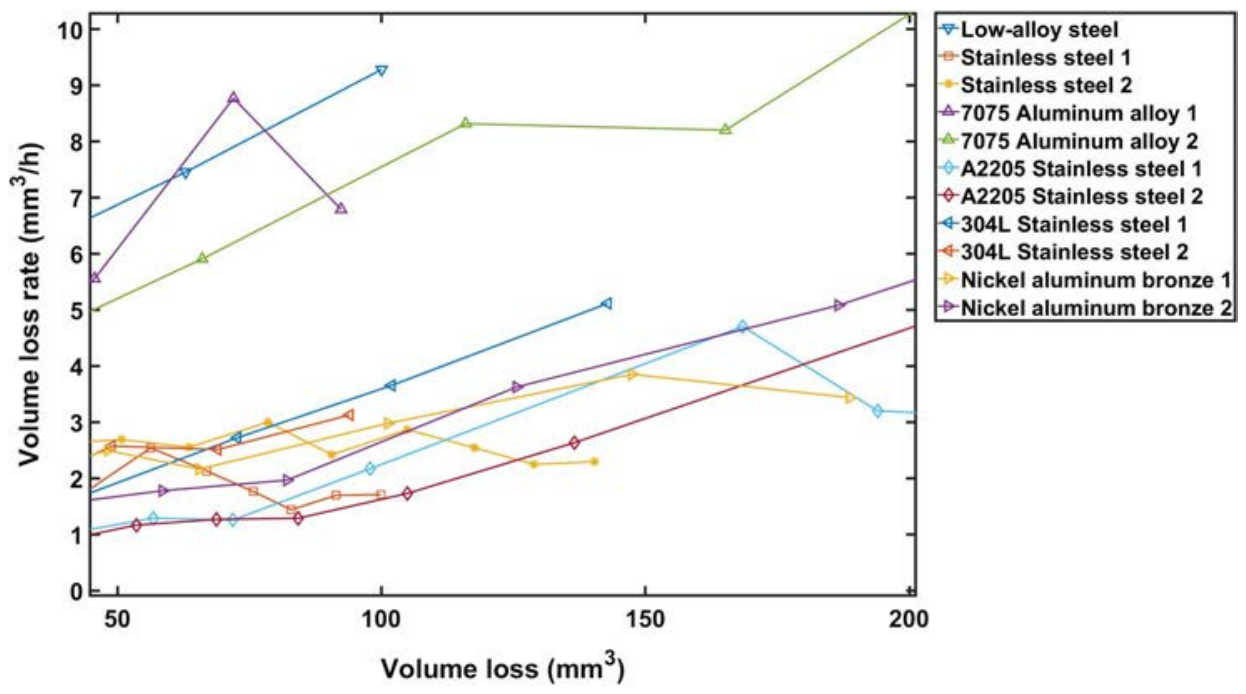
The values for $t_{100}$ and $t_{50}$ are instants interpolated from the polynomial fitted to the experimental points when the volume losses are $100 \mathrm{~mm}^{3}$ and $50 \mathrm{~mm}^{3}$, respectively.

As previously explained, the specimens in our study were a different size to those used in the comparison study. The average steady-state erosion rates and the high strain rate yield stresses for all of the compared materials are presented in Table 2.

The material densities presented in Table 2 are general values, as they were not measured for the materials or individual specimens used in our study. For the two stainless steels, densities are assumed to be the same as that of the low-alloy steel. In the present work, the volume loss rate is preferred over the mass loss rate for defining the erosion rate, thereby reducing the importance of defining the densities accurately.

A lower steady-state volume loss rate indicates higher cavitation erosion resistance. Using this metric, our results show that the low-alloy steel has the poorest resistance to cavitation, falling into the same category as the 7075 aluminum alloy in terms of volume loss rate. The $304 \mathrm{~L}$ stainless steel has a moderate resistance to cavitation and Stainless steel 2 falls into the same category as the C95400 nickel aluminum bronze alloy. Stainless steel 1 and A2205 stainless steel are both superior to all the other tested materials.

The low-alloy steel has a lower yield stress than the two stainless steels, with a strain rate of 2,000 1/s. The low-alloy steel was also tested in a conventional compression test, so both values are presented in the table. The other materials were not tested for their yield stresses in this study, so those values are taken from the literature. The three tested materials are not comparable to the rest of the specimens, as they were measured at different strain rates. However, they may be compared separately. The yield stresses for Stainless steels 1 and 2 are almost equal, although they have different erosion rates. For the other materials, the yield stresses correlate with the erosion rates, so that a higher yield stress corresponds to a lower steady-state erosion rate. It is worth noting that the low-alloy steel has a higher yield stress than the aluminum alloys (if one ignores the different strain rates).

It is noticeable that the low-alloy steel suffered greater mass loss than the 7075 aluminum alloy. In addition, the low-alloy steel started to rust during the experiments as it was in contact with water. This may also have contributed to its high erosion rate. As the metal oxidizes, it degrades the quality of the surface, which is then removed by the cavitation, continuously exposing fresh surface to the water, thus increasing the corrosion rate [33].

An interesting detail that surfaced from this comparison of the two-turbine runner stainless steels is that the one that performed better came from a Francis turbine designed in the 1970s, while the worse-performing one came from a much more recent Francis turbine design (2010s). The low-alloy steel was from a turbine constructed in the 1930s, which was later decommissioned. This detail shows that, at least in this case, cavitation erosion resistance was probably not a known parameter when making material choices at that time. Shifting from steels to stainless steels seems to increase the metal's resistance to cavitation erosion significantly.

As mentioned previously, the erosion rate is dependent on the azimuthal angle, as the evolution of the erosion is not perfectly uniform. This nonuniformity may not have been apparent with the small specimens used in the experiments by Franc et al. [24]. An example of the nonuniformity of erosion evolution is presented in Fig. 9, in which eight curves for eight different azimuthal angles are presented.

The reason for the differences in the erosion rates could be because of differences in the composition of the material within just the one specimen. As cavitation is such a complex process, it is possible that even small differences in the specimen's composition and 
FIG. 9 Volume loss of Stainless steel 2 for all eight specimen azimuthal angles. The incubation time was calculated for each azimuthal angle separately and was then subtracted from the exposure time to negate its effect.

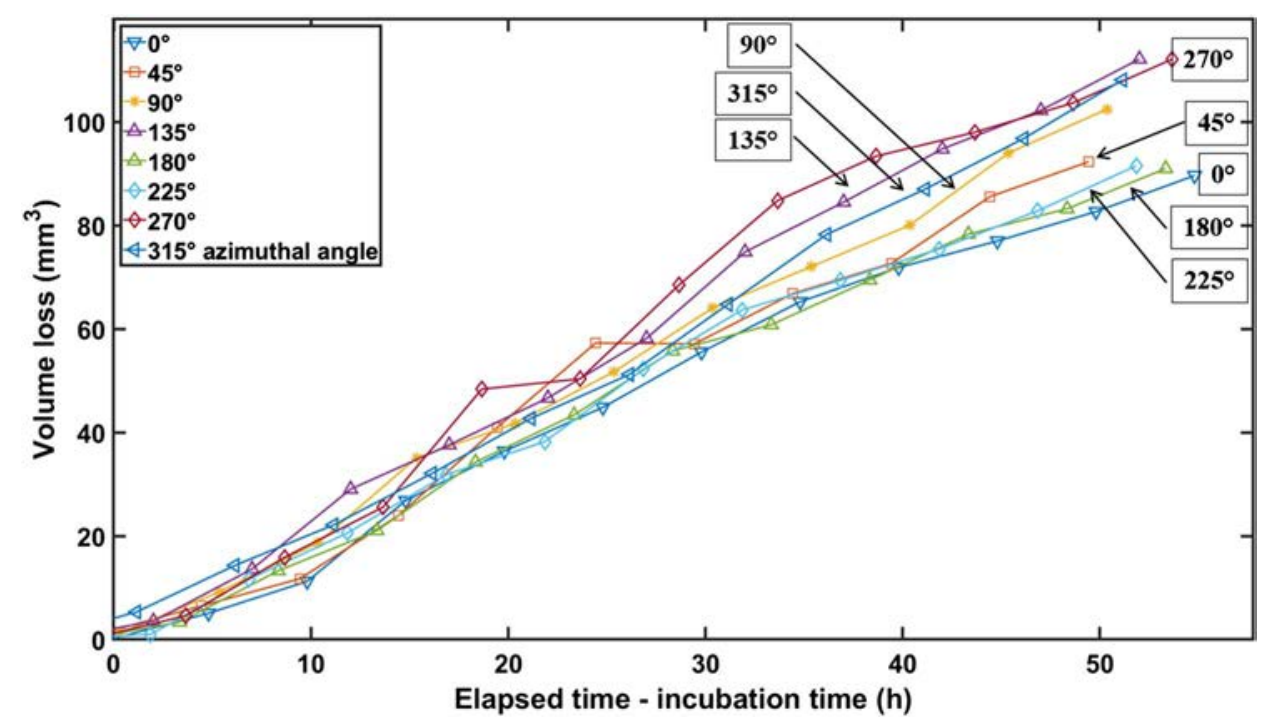

microstructure would lead to different erosion rates. These may that persist even if the erosion process goes on for a long time. The erosion rates do not seem to fall clearly around a single value as the erosion evolves. The strength of cavitation erosion in the cavitation tunnel is assumed to be axisymmetric, and even if this is not absolutely true, turning the specimen between each testing intervals should have negated any nonaxisymmetrical effect.

To study the differences in steady-state volume loss rates within one specimen, the rates were calculated using the same method as before for the four azimuthal angles for the low-alloy steel and for all eight azimuthal angles for the two stainless steels. The resultant steady-state volume loss rates are presented in Table 3.

The differences between the specimen azimuthal angles in the steady-state volume loss rates are significant, especially for the low-alloy steel. The low-alloy steel was not turned between measurements, so nonuniformity in the erosion potential of the cavitation tunnel might be a major reason in the differing erosion rates. The erosion rate follows a pattern in which a relatively high value always has a counterpart falling into the same diagonal. This raises the question as to whether the specimens were completely isotropic. It was initially assumed that they were, as they were manufactured by casting and were cut using methods that do not overly heat the specimen. Small differences in the

\section{TABLE 3}

Steady-state volume loss rates of the studied materials for different specimen azimuthal angles. The specimen azimuthal angle is presented in degrees so that $0^{\circ}$ degrees means north and $180^{\circ}$ degrees means south on the circular specimen surface.

\begin{tabular}{|c|c|c|c|c|c|c|c|c|}
\hline Material & $\begin{array}{c}\text { Rate } 1 \\
\left(\mathrm{~mm}^{3} / \mathrm{h}\right) 0^{\circ}\end{array}$ & $\begin{array}{c}\text { Rate } 2 \\
\left(\mathrm{~mm}^{3} / \mathrm{h}\right) 45^{\circ}\end{array}$ & $\begin{array}{c}\text { Rate } 3 \\
\left(\mathrm{~mm}^{3} / \mathrm{h}\right) 90^{\circ}\end{array}$ & $\begin{array}{c}\text { Rate } 4 \\
\left(\mathrm{~mm}^{3} / \mathrm{h}\right) 135^{\circ}\end{array}$ & $\begin{array}{c}\text { Rate } 5 \\
\left(\mathrm{~mm}^{3} / \mathrm{h}\right) 180^{\circ}\end{array}$ & $\begin{array}{c}\text { Rate } 6 \\
\left(\mathrm{~mm}^{3} / \mathrm{h}\right) 225^{\circ}\end{array}$ & $\begin{array}{c}\text { Rate } 7 \\
\left(\mathrm{~mm}^{3} / \mathrm{h}\right) 270^{\circ}\end{array}$ & $\begin{array}{c}\text { Rate } 8 \\
\left(\mathrm{~mm}^{3} / \mathrm{h}\right) 315^{\circ}\end{array}$ \\
\hline Low-alloy steel & 11.62 & & 5.44 & & 12.38 & & 3.63 & \\
\hline Stainless steel 1 & 1.40 & 1.70 & 2.02 & 2.24 & 1.52 & 1.58 & 2.30 & 2.21 \\
\hline Stainless steel 2 & 4.02 & 2.94 & 3.02 & 2.95 & 3.56 & 2.66 & 2.43 & 2.27 \\
\hline
\end{tabular}


microstructure are expected, as the material solidifies at a different rate depending on the location inside the cast. The fact that the steady-state volume loss rate fluctuates significantly depending on the azimuthal angle clearly indicates that the cavitation erosion resistance of a material cannot properly be defined without looking into its microstructure.

\section{SEM}

SEM images with various magnifications were taken of the specimen surface in order to make this a qualitative study. Fig. 10a-c shows three panoramic images of the eroded areas of the studied materials taken with a $20 \times$ magnification. These images show the center of the specimen on the left, and the right is towards the edge of the specimen.

Although the areas of maximum erosion in the images in Fig. 10 are not exactly aligned, in the actual specimens, the erosion occurred in the same radial location. The discrepancy is due to the image processing, as the panoramic images were constructed from multiple smaller images.

The erosion in the low-alloy steel in Fig. 10a begins abruptly compared to the stainless steels in Fig. $10 \mathrm{~b}-\mathrm{c}$. The erosion in the downstream region after the maximum erosion depth is about 6-mm long for all three materials, while in the upstream region, although it is approximately the same for the stainless steels, it is only about 2-mm long for the lowalloy steel (based on visual observations from these images). The pits and erosion in the upstream region of the stainless steels consist of individual pits and surface roughness, placing the stage of erosion in those regions as somewhere between the incubation and acceleration periods. The downstream regions of all the specimens are rougher than the upstream regions, putting these regions in the acceleration, or even the steady-state, period of erosion evolution.

The exposure time of the low-alloy steel was much lower than that of the stainless steels. As the upstream damage to the stainless steels consists of single pits and surface roughness, it is concluded that the rate of cavitation impacts is much lower upstream of the maximum depth than it is in other regions. Because of the low-alloy steel's lower exposure time, there might be less time for such individual pits to form in the upstream region.

FIG. 10

Panoramic SEM images of

(a) low-alloy steel, (b) Stainless steel 1 and (c) Stainless steel 2 with a $20 \times$ magnification. Flow direction from the specimen center towards the edges is marked with the red arrows between the images.

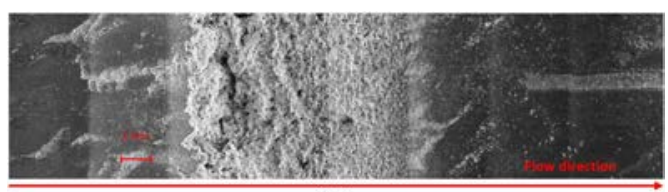

(a)

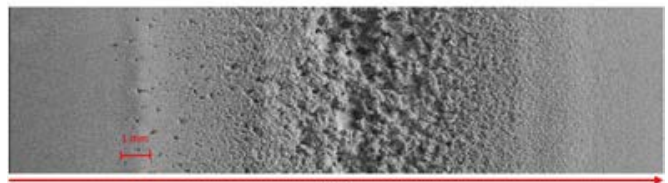

(b)

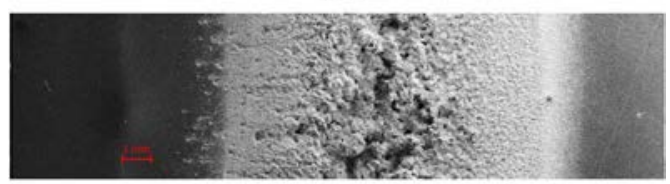

(c) 
Figs. 10 and 11 show SEM images of the low-alloy steel at a greater magnification (200x). The evolving cracks can be seen everywhere, so it may be assumed that these cracks, and any subsequent ruptures, would be a major factor in the rate of material loss, as expected.

In Fig. 11, the eroded surface is uneven and the "valleys" of the erosion pits seem to be deep compared to the surrounding "mountains." The actual depth of the pits could not be defined using the SEM. This image with $200 \times$ magnification shows the overall structure of the highly eroded surface, but it does not tell us much about the erosion mechanisms. When a chunk of the material is removed by rupture, it leaves a smooth surface behind, as can be seen in Fig. 12. The smooth surface is then attacked by subsequent cavitation impacts, leaving small pits that eventually start to overlap.

The 1,000 $\times$ magnification in Fig. 12 offers more insight into the erosion mechanisms. The surface in the middle of the image is relatively smooth, with some small widely-spaced pits in it. The diameter of the small pits is in the range of one $\mu \mathrm{m}$, which corresponds to small cavitation impacts. One possible cause for such a smooth surface could be that a relatively large chunk, microscopic in actual size, of material was removed quite recently. Once the large chunk had been removed, the new smooth surface was only exposed to cavitation for such a short time (the time remaining in the test period) that only the small individual pits are seen.

Fig. 13, at $2000 \times$ magnification, shows the progression of a crack front.

A series of lines, identified by the red arrows, are visible in Fig. 13. As each new impact of sufficient amplitude hits the surface of the material in the vicinity of the crack, the crack front is supposed to jump from one line to the next. This crack propagation ends up with the removal of a micropiece of material that makes the plane of the propagated crack visible, as can be seen in Fig. 12. This pattern is commonly associated with low-cycle fatigue, which supports the idea that cavitation erosion at the intensity generated in the cavitation tunnel is most probably due to low-cycle fatigue.

FIG. 11

Low-alloy steel SEM image erosion detail with $200 x$ magnification. Some of the cracks are marked by red crosses.

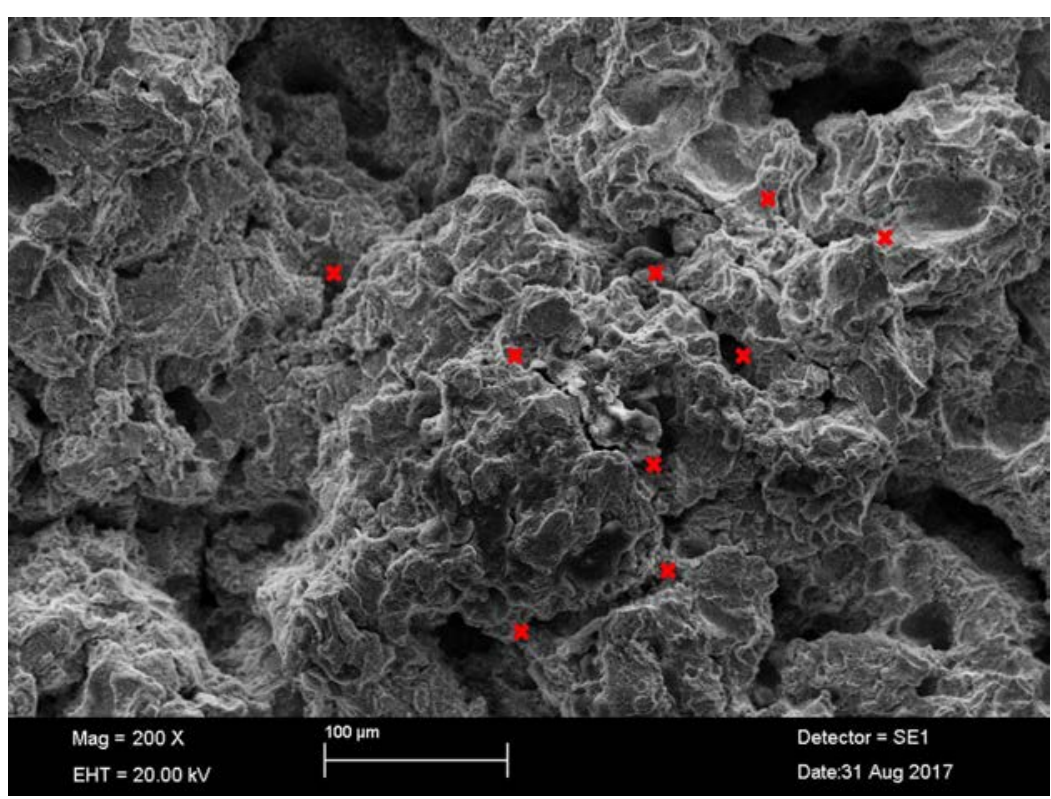


FIG. 12 Stainless steel 1 SEM image erosion detail with 1,000 × magnification. The red lines highlight a relatively smooth surface.

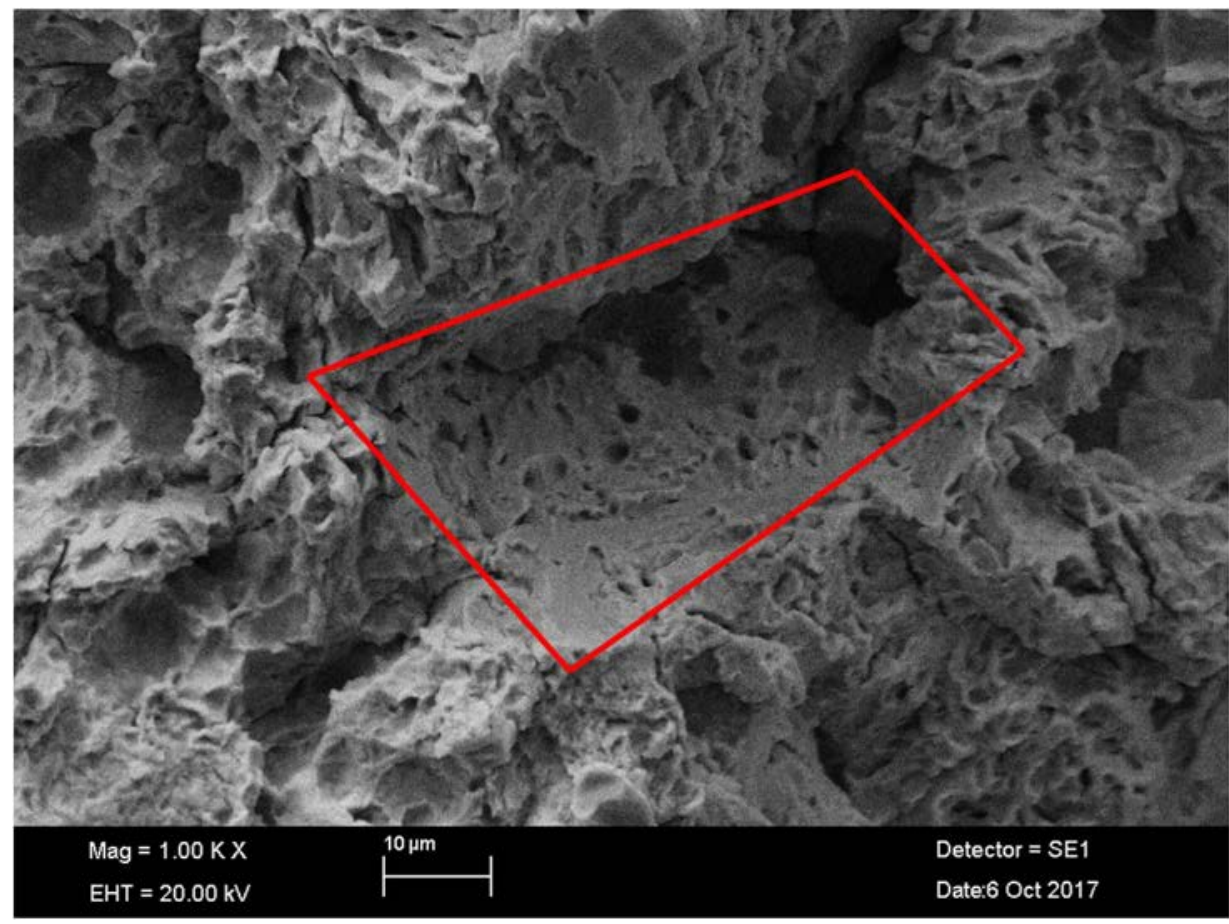

FIG. 13 Successive crack front positions for Stainless steel 1 with 2,000 x magnification. The schematic in the top-right corner describes the crack propagation and the development of the "beach marks."

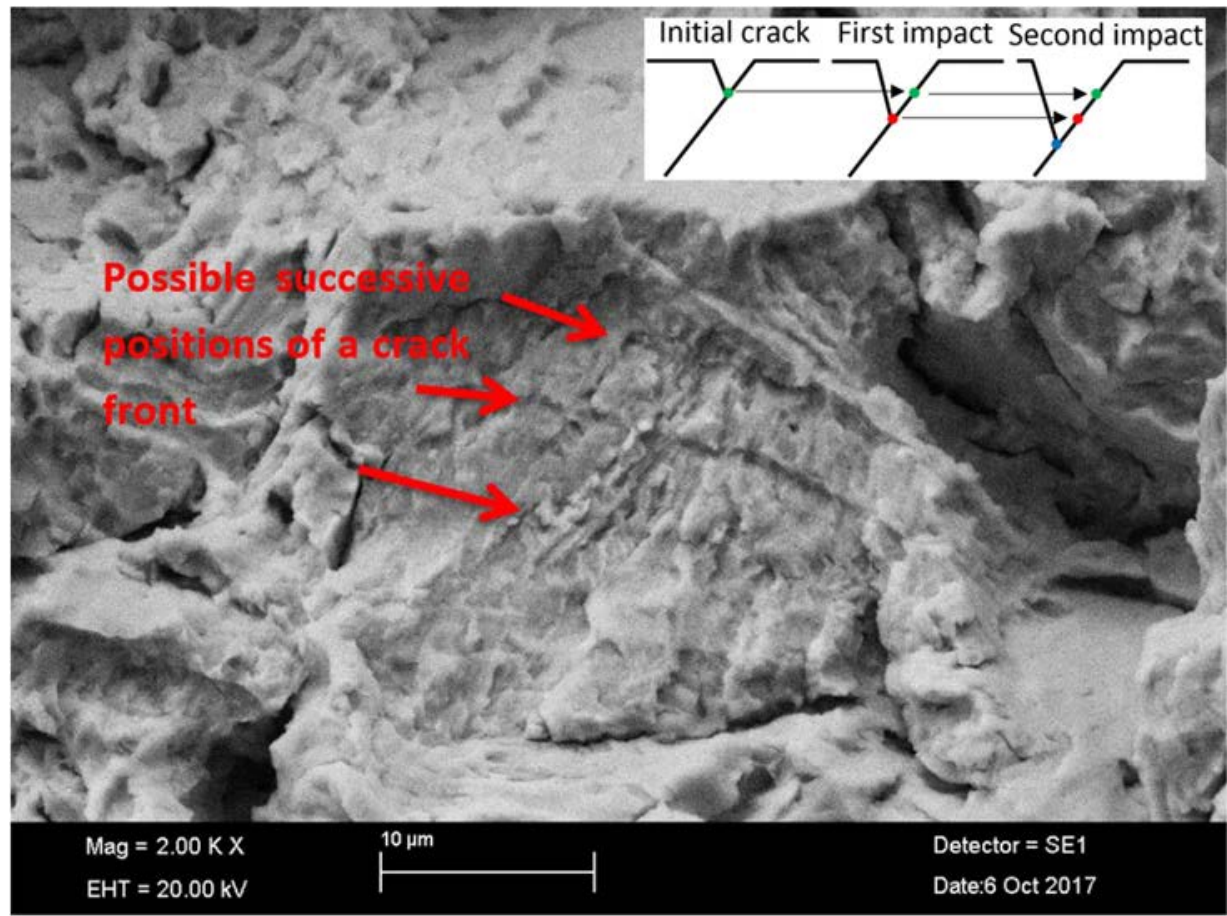


FIG. 14 A SEM image of Stainless steel 2 erosion with 2,000 x magnification. The red lines highlight the assumedly soon-to-be-removed material chunk marked by the red A-letter.

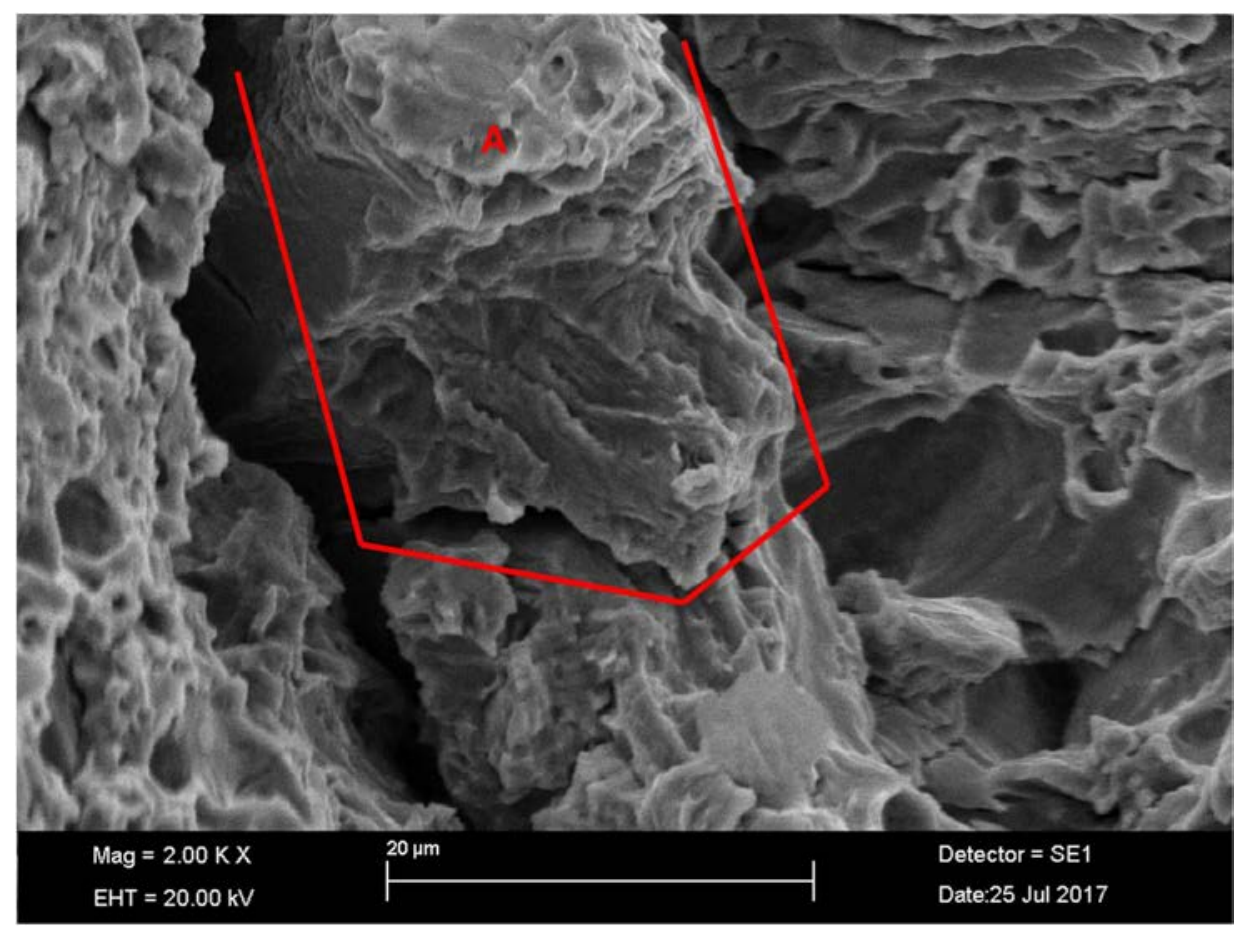

Fig. 14 shows a well-developed crack propagation process with a presumably soon-tobe-removed chunk of material.

The image with $2000 \times$ magnification in Fig. 14 offers some insight into the removal of individual chunks of material. The chunk in the middle of the image is surrounded by large cracks, and it is covered with plastic deformation resulting from cavitation impacts. If the erosion were to continue, the cavitation impacts hitting the chunk of loosened material would eventually cause it to break away.

These observations all support the results and assumptions made in [19,21,22], which is that the erosion mechanism in the mass loss period is probably caused by low-cycle fatigue. Virgin surfaces with several small pits showing where tiny particles have subsequently been removed were found throughout the specimens, as were cracks and soon-to-be-removed chunks.

\section{Conclusions}

Steady-state cavitation erosion rates were studied for one low-alloy steel and two stainless steels (Stainless steel 1 and 2). They were compared to those of 7075 aluminum alloy, C95400 aluminum bronze alloy, 304L stainless steel, and A2205 stainless steel. Steady-state volume loss rate was defined as the average volume loss rate between $50 \mathrm{~mm}^{3}$ and $100 \mathrm{~mm}^{3}$ total volume loss, to mitigate fluctuation and to provide a fair comparison of the materials. It was shown that to properly assess steady-state erosion rate, one has to 
average several erosion processes through the specimen. The stainless steels were specimens from turbines that are of a type that is still in use, so they are relevant in the field of turbine design.

The low-alloy steel had the poorest cavitation erosion resistance, along with the 7075 aluminum alloy. In this study, 304L stainless steel, C95400 aluminum bronze alloy, and Stainless steel 2 had a better resistance than the other materials, while A2205 stainless steel and Stainless steel 1 had the highest cavitation erosion resistance. It was found that the erosion rates differ significantly even within one specimen. This means that assessing a single value for cavitation erosion resistance is problematic, because factors, such as small differences in the local material composition or microstructure, might change the erosion rates significantly. Even minor anisotropies in the specimen material might be the cause of significantly differing erosion rates, as it was observed that the erosion rates are either high or low along the same diagonal in a circular specimen. This means that in hydro machines, cavitation erosion rates may also differ greatly, depending on how, for example, the casting process leads to different grain sizes in the machine.

Materials with low steady-state erosion rates and therefore, high cavitation erosion resistances, generally had a higher yield stress. The yield stress, however, cannot be used alone to estimate the erosion rate, as Stainless steel 2 had a slightly higher yield stress than Stainless steel 1, for example, but it also had a higher erosion rate. Furthermore, the lowalloy steel had a higher yield stress than the 7075 aluminum alloy, but both materials eroded at the same rate. This was probably due to the combined effect of corrosion and cavitation erosion.

The material microstructure analysis showed that Stainless steels 1 and 2 consist of almost $100 \%$ martensite and that the first one has a significantly smaller prior austenite grain size. The prior austenite grain size is related to the impact strength and plasticity, so this could explain the difference in erosion rate between these two martensitic steels.

SEM images were taken from three eroded specimens, and they were analyzed to observe the erosion mechanisms. The images showed the dominating erosion mechanism to be, most probably, low-cycle fatigue. Virgin areas were found, with recently removed material and pits resulting from plastic deformations. Cracks and presumably soon-to-beremoved chunks of material were observed throughout the specimens. So-called "beach marks" were also found, indicating towards low-cycle fatigue.

\section{ACKNOWLEDGMENTS}

The authors would like to thank Business Finland, Fortum Power and Heat Oy, Sandvik Mining and Construction Oy, Valtra Oy, and Teollisuuden Voima Oyj for funding the research and for providing technical support.

\section{References}

[1] Brennen, C. E., "Cavitation Bubble Collapse," Cavitation and Bubble Dynamics, Oxford University Press, Oxford, UK, 1995, pp. 80-108.

[2] Avellan, F., "Introduction to Cavitation in Hydraulic Machinery," presented at the Sixth International Conference on Hydraulic Machinery and Hydrodynamics, Timisoara, Romania, Oct. 21-22, 2004, Politehnica University of Timişoara, Timisoara, Romania.

[3] Kumar, P. and Saini, R. P., "Study of Cavitation in Hydro Turbines-A Review," Renew. Sustainable Energy Rev., Vol. 14, No. 1, 2010, pp. 374-383, https://doi. org/10.1016/j.rser.2009.07.024 
[4] Escaler, X., Egusquiza, E., Farhat, M., Avellan, F., and Coussirat, M., "Detection of Cavitation in Hydraulic Turbines," Mech. Syst. Sig. Process., Vol. 20, No. 4, 2006, pp. 983-1007, https://doi.org/10.1016/j.ymssp.2004.08.006

[5] Berchiche, N., Franc, J. P., and Michel, J. M., "A Cavitation Erosion Model for Ductile Materials,” J. Fluids Eng., Vol. 124, No. 3, 2002, pp. 601-606, https://doi.org/10.1115/ 1.1486474

[6] Franc, J. P., "Incubation Time and Cavitation Erosion Rate of Work-Hardening Materials," J. Fluids Eng., Vol. 131, No. 2, 2009, p. 021303, https://doi.org/10. $1115 / 1.3063646$

[7] Franc, J. P., Chahine, G. L., and Karimi, A., "Pitting and Incubation Period," Advanced Experimental and Numerical Techniques for Cavitation Erosion Prediction, Springer Dordrecht Heidelberg, Heidelberg, Germany, 2014, pp. 37-69.

[8] Zhou, Y. K. and Hammitt, F. G., "Cavitation Erosion Incubation Period," Wear, Vol. 86, No. 2, 1983, pp. 299-313, https://doi.org/10.1016/0043-1648(83)90168-0

[9] Chahine, G. L., Franc, J. P., and Karimi, A., "Mass Loss and Advanced Periods of Erosion," Advanced Experimental and Numerical Techniques for Cavitation Erosion Prediction, Springer Dordrecht Heidelberg, Heidelberg, Germany, 2014, pp. $97-121$.

[10] ASTM G32-10, Standard Test Method for Cavitation Erosion Using Vibratory Apparatus, ASTM International, West Conshohocken, PA, 2010, www.astm.org

[11] Hattori, S., Ishikura, R., and Zhang, Q., "Construction of Database on Cavitation Erosion and Analyses of Carbon Steel Data,” Wear, Vol. 257, Nos. 9-10, 2004, pp. 1022-1029, https://doi.org/10.1016/j.wear.2004.07.002

[12] Hattori, S. and Kitagawa, T., "Analysis of Cavitation Erosion Resistance of Cast Iron and Nonferrous Metals Based on Database and Comparison with Carbon Steel Data," Wear, Vol. 269, Nos. 5-6, 2010, pp. 443-448, https://doi.org/10.1016/ j.wear.2010.04.031

[13] Hattori, S. and Ishikura, R., "Revision of Cavitation Erosion Database and Analysis of Stainless Steel Data,” Wear, Vol. 268, Nos. 1-2, 2010, pp. 109-116, https://doi.org/10. 1016/j.wear.2009.07.005

[14] Kendrick, H., Light, M. S., and Caccese, V., Development of a Cavitation Erosion Resistant Advanced Material System, Report No. UM-MACH-RPT-01-05, Office of Naval Research, Arlington, VA, 2005, 67p.

[15] Chahine, G. L., Franc, J. P., and Karimi, A., "Laboratory Testing Methods of Cavitation Erosion," Advanced Experimental and Numerical Techniques for Cavitation Erosion Prediction, Springer Dordrecht Heidelberg, Heidelberg, Germany, 2014, pp. 21-35.

[16] Soyama, H. and Futakawa, M., "Estimation of Incubation Time of Cavitation Erosion for Various Cavitating Conditions," Tribol. Lett., Vol. 17, No. 1, 2004, pp. 27-30, https://doi.org/10.1023/B:TRIL.0000017415.79517.8c

[17] Karimi, A., "Cavitation Erosion of a Duplex Stainless Steel," Mater. Sci. Eng., Vol. 86, 1987, pp. 191-203, https://doi.org/10.1016/0025-5416(87)90452-6

[18] Karimi, A. and Avellan, F., "Comparison of Erosion Mechanisms in Different Types of Cavitation," Wear, Vol. 113, No. 3, 1986, pp. 305-322, https://doi.org/10.1016/ 0043-1648(86)90031-1

[19] Fortes Patella, R., Choffat, T., Reboud, J., and Archer, A., "Mass Loss Simulation in Cavitation Erosion: Fatigue Criterion Approach," Wear, Vol. 300, No. 1, 2013, pp. 205-215, https://doi.org/10.1016/j.wear.2013.01.118

[20] Bathias, C. and Pineau, A., "Low-Cycle Fatigue," Fatigue of Materials and Structures: Fundamentals, John Wiley \& Sons, New York, NY, 2010, pp. 113-116, https://doi. org/10.1002/9781118623435

[21] Balyts'kyi, O. I. and Chmiel, J., "Resistance of Plate Shipbuilding Steels to CavitationErosion and Fatigue Fracture," Mater. Sci., Vol. 50, No. 5, 2015, pp. 736-739, https:// doi.org/10.1007/s11003-015-9779-y 
[22] Abouel-Kasem, A., Emara, K. M., and Ahmed, S. M., "Characterizing Cavitation Erosion Particles by Analysis of SEM Images," Tribol. Int., Vol. 42, No. 1, 2009, pp. 130-136, https://doi.org/10.1016/j.triboint.2008.05.008

[23] Laboratoire LEGI, "The PREVERO Cavitation Erosion Tunnel," Laboratoire LEGI, 2018, https://web.archive.org/web/20180327065723/https://www.legi.grenoble-inp. fr/web/spip.php?article1265\&lang=fr (accessed 27 March 2018).

[24] Franc, J. P., Riondet, M., Karimi, A., and Chahine, G. L., "Material and Velocity Effects on Cavitation Erosion Pitting," Wear, Vols. 274-275, 2012, pp. 248-259, https://doi.org/10.1016/j.wear.2011.09.006

[25] Deplancke, T., Lame, O., Cavaille, J., Fivel, M., Riondet, M., and Franc, J. P., "Outstanding Cavitation Erosion Resistance of Ultra High Molecular Weight Polyethylene (UHMWPE) Coatings," Wear, Vols. 328-329, 2015, pp. 301-308, https://doi.org/10.1016/j.wear.2015.01.077

[26] Ylönen, M., Saarenrinne, P., Miettinen, J., Franc, J. P., and Fivel, M., "Cavitation Bubble Collapse Monitoring by Acoustic Emission in Laboratory Testing," presented at the Tenth International Symposium on Cavitation (CAV2018), Baltimore, MD, May 14-16, 2018, Johns Hopkins University, Baltimore, MD-unpublished.

[27] Chahine, G. L., Franc, J. P., and Karimi, A., "Cavitation and Cavitation Erosion," Advanced Experimental and Numerical Techniques for Cavitation Erosion Prediction, Springer Dordrecht Heidelberg, Heidelberg, Germany, 2014, pp. 3-20, https://doi.org/10.1007/978-94-017-8539-6

[28] ASTM E112-13, Standard Test Methods for Determining Average Grain Size, ASTM International, West Conshohocken, PA, 2013, www.astm.org

[29] Morito, S., Yoshida, H., Maki, T., and Huang, X., "Effect of Block Size on the Strength of Lath Martensite in Low Carbon Steels," Mater. Sci. Eng. A, Vols. 438-440, 2006, pp. 237-240, https://doi.org/10.1016/j.msea.2005.12.048

[30] Roy, S. C., 2015, "Modeling and Analysis of Material Behavior during Cavitation Erosion," Ph.D. dissertation, Université Grenoble Alpes, Grenoble, France.

[31] Zavaleta Gutiérrez, N., Luppo, M. I., Danon, C. A., Toda-Caraballo, I., Capdevila, C., and García, D. A., "Heterogeneous Austenite Grain Growth in Martensitic 9Cr Steel: Coupled Influence of Initial Metallurgical State and Heating Rate," Mater. Sci. Technol., Vol. 29, No. 10, 2013, pp. 1254-1266, https://doi.org/10.1179/1743284713Y.0000000271

[32] Kim, H. J., Kim, Y. H., and Morris, Jr., J. W., "Thermal Mechanisms of Grain and Packet Refinement in a Lath Martensitic Steel," ISIJ Int., Vol. 38, No. 11, 1998, pp. 1277-1285, https://doi.org/10.2355/isijinternational.38.1277

[33] Ryl, J., Darowicki, K., and Slepski, P., "Evaluation of Cavitation Erosion-Corrosion Degradation of Mild Steel by Means of Dynamic Impedance Spectroscopy in Galvanostatic Mode," Corros. Sci., Vol. 53, No. 5, 2011, pp. 1873-1879, https:// doi.org/10.1016/j.corsci.2011.02.004

[34] MatWeb, "Overview of Materials for Low Alloy Steel," 2018, MatWeb Material Property Data, http://web.archive.org/web/20180921140451/http://www.matweb. com/search/datasheettext.aspx? matguid=d1bdbccde4da4da4a9dbb8918d783b29 (accessed 27 March 2018).

[35] MatWeb, “Aluminum 7075-O,” 2018, Matweb Material Property Data, http://www. matweb.com/search/DataSheet.aspx?MatGUID=da98aea5e9de44138a7d28782f60a8 $36 \& c k c k=1$ (accessed 27 March 2018).

[36] MatWeb, "Carlson 2205 (UNS S32205) Duplex Stainless Steel," 2018, MatWeb Material Property Data, http://web.archive.org/web/20180921140647/http://www.matweb.com/ search/datasheettext.aspx?matguid=086d8b05d09c4963b95253bd278dc4f4 (accessed 27 March 2018).

[37] MatWeb, “AISI Type 304L Stainless Steel," 2018, MatWeb Material Property Data, http:// web.archive.org/web/20180921140725/http://www.matweb.com/search/datasheet_print. aspx?matguid=e2147b8f727343b0b0d51efe02a6127e (accessed 27 March 2018).

[38] MatWeb, "Aluminum Bronze, UNS C95400, Copper Casting Alloy, As Cast," 2018, MatWeb Material Property Data, http://web.archive.org/web/20180921140819/http:// www.matweb.com/search/datasheettext.aspx?matid=11963 (accessed 27 March 2018). 